\title{
Copeptin, Pro-atrial Natriuretic Peptide and Pro- adrenomedullin as Markers of Hypoxic Stress in Patients With Obstructive Sleep Apnea - a Prospective Intervention Study
}

\section{Meropi Karakioulaki}

Universitatsspital Basel

\section{Peter Grendelmeier}

Kantonsspital Baselland

Werner Strobel

Universitatsspital Basel

Thomas Schmid

Universitatsspital Basel

Kathleen Jahn

Universitatsspital Basel

Leticia Grize

Universitatsspital Basel

Michael Tamm

Universitatsspital Basel

Daiana Stolz ( Daiana.Stolz@usb.ch )

Universitatsspital Basel

\section{Research}

Keywords: OSA, CPAP, proADM, copeptin, proAMP

Posted Date: January 21st, 2021

DOI: https://doi.org/10.21203/rs.3.rs-150708/v1

License: (c) (1) This work is licensed under a Creative Commons Attribution 4.0 International License. Read Full License

Version of Record: A version of this preprint was published at Respiratory Research on April 20th, 2021.

See the published version at https://doi.org/10.1186/s12931-021-01704-0. 


\section{Abstract}

Study Objectives: Obstructive sleep apnea (OSA) might lead to oxidative stress, inflammation and elevated circulating copeptin, proANP and proADM levels. We aimed to evaluate whether the levels of these prohormones are higher in patients with OSA and whether they might change under continuous positive airway pressure (CPAP) therapy, serving as potential proxies for the diagnosis and therapyresponse in OSA.

Methods: A total of 310 patients with suspicion of OSA were recruited. Screening for OSA was performed using overnight pulse oximetry followed by polygraphy and a venous puncture in the morning. All patients diagnosed with OSA underwent CPAP adaptation. A venous puncture was conducted in the night before CPAP and in the following morning. At 1 and 6 months of treatment, polygraphy was performed, followed by a venous puncture in the morning. In the acquired blood, copeptin, proANP and proADM levels were measured.

Results: We analyzed 232 patients with OSA and 30 patients without OSA. Our results indicated that only copeptin levels differed significantly among patients with and without OSA at baseline. In OSA patients, the levels of proADM significantly changed after 1 and 6 months on CPAP therapy, when compared to baseline $(p<0.001$ and $p=0.020)$. Additionally, proANP levels significantly decreased after 12 hours on CPAP therapy, as compared to baseline levels $(p<0.001)$.

Conclusions: Copeptin is significantly associated with the presence of OSA. ProANP levels might serve as a potential proxy for the acute response to non-invasive ventilation (12 hours), while proADM reflects the long-term response (1 and 6 months).

\section{Background}

Obstructive sleep apnea (OSA) is a disorder characterised by repetitive upper airway obstruction during sleep, that might lead to intermittent hypoxia, sleep fragmentation and daytime symptoms such as excessive sleepiness, the so-called obstructive sleep apnea syndrome (OSAS). (1) Important factors in the progression of the disease include: baseline obesity, older age and the presence of snoring. (1)

Compared with persons without sleep apnea, patients with obstructive sleep apnea have heightened peripheral chemoreflex sensitivity, resulting in an increased ventilatory response during hypoxemic episodes. (2) Chemoreflex-mediated vascular sympathetic activation and vasoconstriction intensify as apnea progresses, in association with increases in blood pressure. (3) Increased sympathetic activity, repetitive rises in blood pressure and apnea-induced stress in OSA may also contribute as a trigger to release several prohormones, such as the pro-atrial natriuretic peptide (proANP), the pro-adrenomedullin (proADM) and the pro-arginine vasopressin (proAVP or copeptin). $(4,5)$

ProADM is a stable mid-regional fragment that is produced after degradation of ADM. (6) ProADM has been found to be increased in hypoxemia and to have an anti-inflammatory effect on bronchial epithelial 
cells and airway smooth muscle. (7) ADM counteracts with the renin-angiotensin-aldosterone system (8) and stimulates angiogenesis. $(9,10)$ Moreover, oxidative stress $(11,12)$, inflammation $(13)$ and apoptosis (14-16) can induce ADM synthesis. All of these stimuli might be active in the case of OSA.

Arginine vasopressin (AVP) is one of the key hormones of water homeostasis and is produced by hypothalamic neurons. (4) AVP has vasoconstrictor and antidiuretic properties and can restore vascular tone in vasodilatory hypotension. (17) Its release is induced by different stimuli including hypotension, hypoxia, hyperosmolarity, acidosis, infections and various cytokines. (18) AVP is derived from a larger precursor (preproAVP) along with two other peptides: neurophysin II and copeptin. (19) Copeptin is a more stable peptide and its concentrations mirror that of AVP.

Atrial natriuretic peptide (ANP) is a family member of the natriuretic peptides. (4) Its biological role encompasses natriuresis, vasodilation and inhibition of the renin-angiotensin-aldosterone axis and the sympathetic nervous system. (20-22) ProANP, the precursor ANP hormone, is secreted in an equimolar ratio to ANP. As a result of its longer half-life, plasma levels of proANP are at least ten times higher than those of ANP (23) and due to its more stable nature, proANP is considered to be more applicable in clinical practice. (24) Moreover, ANP plays an important role in the regulation of blood pressure, sodium and volume homeostasis and is secreted into the circulation in response to a variety of stimuli, including acute hypoxia (25) and atrial stretch, which occurs in response to pressure and volume loading. (26)

OSAS-induced hypoxia, hemodynamic effects, sympathetic activation, vascular endothelial dysfunction, metabolic dysregulation, oxidative stress as well as inflammation might lead to elevated levels of circulating copeptin, proANP and proADM levels. The objective of this study was to evaluate whether copeptin, proANP and proADM levels are higher in patients with OSA and whether they might change under continuous positive airway pressure (CPAP) therapy, serving as potential proxies for the diagnosis and therapy-response in OSA.

\section{Methods}

\section{Study design}

This is a prospective, observational longitudinal multicenter study. The study was approved by the local Institutional Review Board (EKBB 17010) and was conducted in accordance with the principles of the Helsinki declaration. Ambulatory patients presenting with suspicion of sleep apnea to a respiratory physician, either in private practice or at a tertiary care hospital, during a period of 31 months were considered for inclusion. After providing written informed consent, patients were assessed in terms of relevant medical history and current medical status. Demographics, vital signs, height, weight and the Epworth Sleepiness Scale (ESS) were recorded and screening for OSA was performed using overnight pulse oximetry (Fig. 1). Thereafter, patients underwent polygraphy, followed by a venous puncture in the morning (6-9 am). All patients with OSA spent another night at the center to initiate CPAP therapy. Vital signs were measured and a venous puncture was conducted in the night before CPAP (8-10 pm) and in 
the following morning (6-9 am). In the acquired blood, copeptin, pro-ANP and pro-ADM levels were measured. At one 1 and 6 months of treatment, polygraphy was performed at the center, followed by a venous puncture in the following morning (6-9 am) (Fig. 1, Supplementary table 1).

\section{Study population}

A total of 310 patients with suspicion of OSA were screened for the study. The inclusion criteria were: age $\geq 18$ and suspicion of OSA. We excluded patients with mental disorders, which could hinder their judgment concerning study participation, with severe co-morbidities that could result in a lower than 6 months life expectancy, with planned emigration or relocation within the country during the study period, as well as women, who were pregnant or were breast-feeding.

\section{Examinations}

Polygraphy was conducted according to the American Academy of Sleep Medicine recommendations (27) using a commercially available device (WatchPAT ${ }^{\text {TM }} 200$ Unified, Itamar medical). The following parameters were measured via three points of contact: Peripheral arterial tonometry signal, heart rate, oximetry, actigraphy, body position, snoring, chest motion, sleep efficiency and sleep stage distribution. Apnea-hypopnea index (AHI), respiratory disturbance index and oxygen desaturation index (ODI) based on true sleep time and sleep staging were assessed. Apnea was defined as complete cessation of airflow for $\geq 10$ seconds. Mild sleep apnea was defined as $5 \leq \mathrm{AHI} \leq 15$, moderate sleep apnea as $15<\mathrm{AHI} \leq 30$ and severe sleep apnea as $A H I>30$. OSAS was defined as an $A H I>5$ with presence of daytime symptoms, such as sleepiness or cognitive deficits attributed to sleep apnea. Patients with an $A H I \geq 5$ and an ESS $<10$ were diagnosed with OSAS without symptoms of sleepiness, while patients with an AHI $\geq 5$ and an ESS $\geq 10$ were diagnosed with OSAS with symptoms of sleepiness.

\section{Laboratory analysis}

Copeptin was measured using $50 \mu$ of serum by a sandwich immunoassay (CT-proAVP LIA; BRAHMS AG; Hennigsdorf/Berlin, Germany). (28) The lower detection limit of the assay was $1.7 \mathrm{pmol} / \mathrm{l}$, and the functional assay sensitivity (defined as the lowest value with an intraassay coefficient of variation $<20 \%$ ) was $2.25 \mathrm{pmol} / \mathrm{l}$. (28) ProANP measurements were performed in $50 \mu \mathrm{l}$ of serum using a test based on time-resolved amplified cryptate emission (TRACE) technology (MR-proANP KRYPTOR; BRAHMS AG; Hennigsdorf, Germany). (29) The lower detection limit of the assay was $6 \mathrm{pmol} / \mathrm{I}$ and the functional assay sensitivity was $23 \mathrm{pmol} / \mathrm{l}$. ProADM was detected in $50 \mu \mathrm{l}$ of serum using a sandwich immunoassay (MR-proADM, BRAHMS AG, Hennigsdorf, Berlin, Germany). (30) The assay had an analytical detection limit of $0.08 \mathrm{nmol} / \mathrm{I}$ and a functional assay sensitivity of $0.12 \mathrm{nmol} / \mathrm{l}$.

\section{Statistical Analysis}

The results are presented as the mean (standard deviation) for all variables that were normally distributed, and as the median (25th to 75th percentile) for variables that were not normally distributed. Differences between groups were evaluated using the Mann-Whitney $\mathrm{U}$, Kruskal Wallis and Fisher's Exact tests. Paired comparison and outcome measurements between different visits during the study were 
examined using the Wilcoxon sign rank test. Correlations between biomarker levels and patient characteristics were performed using the Spearman's rank correlation.

Single variate associations between prohormone levels at baseline and patient diagnostic characteristics were examined using mixed linear regression models. The multivariate associations between biomarker levels at baseline and patient diagnostic characteristics (those with $p<0.05$ in single variate associations) were examined by inclusion of all relevant factors in the model, checking for multicollinearity. No sign of multi-collinearity was observed for any biomarker (tolerance $>0.10$, Variance inflation < 10). Moreover, the associations of prohormone levels with AHI, ESS and ODI severity scores were conducted for all visits utilizing mixed linear models. In all models, the visit factor was included in the model as a fix effect and the subject factor as a random effect. For non-parametric variables we reported the adjusted geometric mean and the effect as the $10^{\text {Beta }}$. All tests were two-tailed; $p<0.05$ was defined as significant.

\section{Sample size calculation}

Sample size was calculated using the decrease in median circulating copeptin after 1 month of CPAP treatment as the primary end-point. A sample size of 270 participants was expected to achieve a statistical power of $95 \%$ to detect an absolute decrease of copeptin of $25 \%$ (from 10.55 to 7.91 considering a standard deviation of 8.5) after 1 month of treatment. Considering a 10\% lost to follow-up, we included 310 patients in the study.

\section{Results}

\section{Patient Characteristics}

310 patients were included in the study. A total of 48 patients restrained from additional testing after pulsoxymetry, leading to the participation of 262 patients. In 30 of them, OSA could be excluded. Out of the 232 patients with OSA, $116(50 \%)$ of them reported daytime sleepiness (ESS $\geq 10)$. Moreover, the patients were very well distributed among the OSA severity levels, based on their AHI score, as 86 (37.1\%) patients had mild OSA, 78 (33.6\%) had moderate OSA, and 68 (29.3\%) severe OSA. The average daily use of CPAP during the first therapeutic night was 7.5 (6.3-8.8) hours (AHI: 13.2 \pm 11.1 ), during the first month on CPAP: 5.0 (3.5-6.5) hours (AHI: $4.5 \pm 9.1$ ) and during the first six months on CPAP: 5.0 (3.36.0) hours (AHI: $3.6 \pm 5.9$ ). The majority of the participants were good responders, as only 6 patients deteriorated despite being on CPAP therapy, presenting with an increase in their AHI score in 1 month $(n=$ 2 patients) and 6 months of therapy ( $n=4$ patients), as compared to the AHI score of the previous visit. The descriptive characteristics of the patients are depicted in Table 1. 
Table 1

Baseline descriptive characteristics of the patients included in the study.

\begin{tabular}{|c|c|c|c|}
\hline Characteristics & $\begin{array}{l}\text { Patients with OSA } \\
N=232\end{array}$ & $\begin{array}{l}\text { Patients without OSA } \\
N=30\end{array}$ & P-value \\
\hline Age $($ mean $\pm S D)$ & $54.9 \pm 13.1$ & $47.9 \pm 13.1$ & 0.004 \# \\
\hline Gender $[\mathrm{N},(\%$ male $)]$ & $182(78.4)$ & $15(50)$ & $0.001 \S$ \\
\hline Pack years (mean $\pm S D$ ) & $17.3 \pm 24.4$ & $14.6 \pm 15.1$ & $0.675 \#$ \\
\hline $\mathrm{BMI}($ mean $\pm \mathrm{SD})$ & $31.3 \pm 5.7$ & $26.5 \pm 4.6$ & $<0.001 \#$ \\
\hline ODI (mean \pm SD) & $18.1 / h \pm 15.3$ & $2.3 / h \pm 2.2$ & $<0.001 \#$ \\
\hline $\mathrm{AHI}($ mean $\pm \mathrm{SD})$ & $25.8 / \mathrm{h} \pm 19.0$ & $2.6 / \mathrm{h} \pm 1.4$ & $<0.001 \#$ \\
\hline Mild OSA $(5 \leq \mathrm{AHI}<15)$ & $10.28 / h \pm 2.90$ & & \\
\hline Moderate OSA $(15 \leq \mathrm{AHI}<30)$ & $20.81 / h \pm 4.19$ & & \\
\hline Severe OSA $(\mathrm{AHI} \geq 30)$ & $49.56 / \mathrm{h} \pm 17.31$ & & \\
\hline \multicolumn{4}{|l|}{ Treatment* } \\
\hline -Clopidogrel, Prasugrel & $46 / 224(20.5 \%)$ & $2 / 30(6.7 \%)$ & $0.082 \S$ \\
\hline -Diuretic & $40 / 223(17.9 \%)$ & $3 / 30(10.0 \%)$ & $0.436 \S$ \\
\hline -Statin & $62 / 225(27.5 \%)$ & $3 / 30(10.0 \%)$ & $0.044 \S$ \\
\hline$-A C E I$ & $85 / 222(38.3 \%)$ & $5 / 30(16.7 \%)$ & $0.025 \S$ \\
\hline -Calcium Antagonists & $25 / 220(11.4 \%)$ & $2 / 30(6.7 \%)$ & $0.752 \S$ \\
\hline -Beta Blocker & $52 / 222(23.4 \%)$ & $3 / 29(10.3 \%)$ & $0.151 \S$ \\
\hline -Oral Antidiabetic & $33 / 224(14.7 \%)$ & $1 / 30(3.3 \%)$ & $0.147 \S$ \\
\hline -Insulin & $6 / 224(2.7 \%)$ & $1 / 30(3.3 \%)$ & $0.590 \S$ \\
\hline -Anti-depressive & $37 / 224(16.5 \%)$ & $6 / 30(20.0 \%)$ & $0.609 \S$ \\
\hline -Sedatives & $23 / 222(10.4 \%)$ & $8 / 30(26.7 \%)$ & $0.018 \S$ \\
\hline
\end{tabular}

OSA = Obstructive Sleep Apnea, SD = Standard Deviation, $\mathbf{N}=$ Number, $\mathbf{B M I}=$ Body Mass Index, ODI = Oxygen Desaturation Index, AHI = Apnea Hypopnea Index, ACE I = Angiotensin Converting Enzyme Inhibitors, COPD = Chronic Obstructive Pulmonary Disease, ESS = Epworth Sleepiness Scale, IQR = Interquartile Range, $\min =$ minutes

*missing data

\# Calculated using the Mann-Whitney U test

$\S$ Calculated using the Fisher's Exact test 


\begin{tabular}{|c|c|c|c|}
\hline \multirow[t]{2}{*}{ Characteristics } & Patients with OSA & Patients without OSA & P-value \\
\hline & $N=232$ & \multicolumn{2}{|l|}{$N=30$} \\
\hline \multicolumn{4}{|l|}{ Comorbidities* } \\
\hline -cerebrovascular disease & $14 / 229(6.1 \%)$ & $1 / 30(3.3 \%)$ & $0.706 \S$ \\
\hline -heart failure & $12 / 239(5.2 \%)$ & $1 / 30(3.3 \%)$ & $0.722 \S$ \\
\hline -myocardial infarction & $10 / 230(4.4 \%)$ & $1 / 30(3.3 \%)$ & $1.000 \S$ \\
\hline -gastric ulcer & $10 / 230(4.4 \%)$ & $1 / 30(3.3 \%)$ & $1.000 \S$ \\
\hline -arterial hypertension & $108 / 230(47.0 \%)$ & $7 / 30(23.3 \%)$ & $0.018 \S$ \\
\hline -coronary artery disease & $20 / 230(8.7 \%)$ & $1 / 30(3.3 \%)$ & $0.484 \S$ \\
\hline -alcohol dependence & $10 / 230(4.4 \%)$ & $1 / 30(3.3 \%)$ & $1.000 \S$ \\
\hline -COPD & $10 / 230(4.4 \%)$ & $0 / 30(0 \%)$ & $0.611 \S$ \\
\hline -allergy & $37 / 229(16.2 \%)$ & $6 / 30(20.0 \%)$ & $0.603 \S$ \\
\hline -diabetes mellitus & $40 / 230(17.4 \%)$ & $4 / 30(13.3 \%)$ & $0.796 \S$ \\
\hline \multicolumn{4}{|l|}{ Sleep characteristics * } \\
\hline -Snoring & $211 / 225(93.7 \%)$ & 23/30 (76.7\%) & $0.006 \S$ \\
\hline -Breathing pauses & $150 / 222(67.6 \%)$ & $14 / 28(50.0 \%)$ & $0.090 \S$ \\
\hline -Insomnia & $39 / 222(17.6 \%)$ & 10/30 (33.3\%) & $0.050 \S$ \\
\hline -Restless legs & $23 / 219(10.0 \%)$ & $5 / 28(17.9 \%)$ & $0.336 \S$ \\
\hline -Nycturia & $101 / 221(45.7 \%)$ & $9 / 30(30.0 \%)$ & $0.119 \S$ \\
\hline -Headache & $40 / 217(18.4 \%)$ & $8 / 27(29.6 \%)$ & $0.198 \S$ \\
\hline -ESS [median, (IQR)] & $10.0(6.0-13.0)$ & $12.0(5.0-14.0)$ & $0.215 \#$ \\
\hline -Sleep duration (hours) (mean \pm SD) & $7.4 \pm 1.5$ & $7.3 \pm 1.7$ & 0.770 \# \\
\hline -Sleep latency (min) & $15.6 \pm 19.5$ & $35.4 \pm 60.9$ & 0.061 \# \\
\hline \multicolumn{4}{|c|}{$\begin{array}{l}\text { OSA = Obstructive Sleep Apnea, SD = Standard Deviation, } \mathrm{N}=\text { Number, } \mathrm{BMI}=\text { Body Mass Index, ODI = } \\
\text { Oxygen Desaturation Index, AHI = Apnea Hypopnea Index, ACE I = Angiotensin Converting Enzyme } \\
\text { Inhibitors, COPD = Chronic Obstructive Pulmonary Disease, ESS = Epworth Sleepiness Scale, IQR = } \\
\text { Interquartile Range, min = minutes }\end{array}$} \\
\hline \multicolumn{4}{|l|}{ *missing data } \\
\hline \multicolumn{4}{|c|}{ \# Calculated using the Mann-Whitney U test } \\
\hline \multicolumn{4}{|c|}{$\S$ Calculated using the Fisher's Exact test } \\
\hline
\end{tabular}




\section{Prohormone levels as biomarkers for the diagnosis of OSA}

When we compared the levels of the three prohormones among patients with and without OSA at baseline, our results indicated that copeptin levels were significantly higher in OSA patients, but there was no significant difference in the levels of $\operatorname{proADM}(p=0.069)$ or proANP $(p=0.086$, Fig. 2$)$.

When we compared the levels of the three prohormones in the morning (6-9 am, at baseline) and evening (8-10 pm, before CPAP initiation) in patients with OSA, there was a circadian change in proADM levels, which increased in the evening and in proANP levels, which decreased in the evening (Fig. 3).

Additionally, within the OSA patient group, our results indicated that there was no difference in the levels of proADM $(p=0.503)$, proANP $(p=0.998)$ and copeptin $(p=0.207)$ among patients with and without OSAS. Additionally, there was no difference in the level of the three prohormones among patients with mild, moderate and severe OSA, as assessed by the AHI, at baseline $(p=0.222, p=0.672, p=0.375$ respectively for proADM, proANP and copeptin). These differences remained non- significant, even after adjusting for age and gender.

The baseline levels of all three biomarkers were significantly associated with pack-years, number of comorbidities and medications (Supplementary table 2). Moreover, proANP and proADM were associated with age, while on the other hand copeptin and proADM were associated with gender, BMI and neck circumference. Similarly, proADM and proANP levels were significantly associated with nocturia (Supplementary table 2). Our results further indicated that proANP and proADM levels at baseline correlated with mean saturation (rho $=-0.221, p=0.008$ and rho $=-0.312, p<0.001$ accordingly, Table 2). ProADM levels at baseline were correlated with duration of hypoxemia ( $r h o=0.297, p<0.001$ ), periodic limb movements of sleep ( $r h o=0.259, p=0.014$ ) and sleep efficiency (rho $=-0.250, p=0.015$ ), while copeptin was significantly correlated with sleep latency (rho=-0.216, $p=0.035$, Table 2 ). 
Table 2

Correlations between biomarker levels at baseline and various sleep parameters in patients with OSA.

\begin{tabular}{|c|c|c|c|c|}
\hline Correlation of & With & $\mathbf{N}$ & rho & p-value \\
\hline Copeptin & \multirow[t]{3}{*}{ ODI } & 142 & 0.105 & 0.214 \\
\hline proANP & & 142 & -0.054 & 0.526 \\
\hline proADM & & 142 & 0.101 & 0.233 \\
\hline Copeptin & \multirow[t]{3}{*}{ Oxygen saturation at rest } & 141 & -0.133 & 0.116 \\
\hline proANP & & 141 & -0.095 & 0.261 \\
\hline proADM & & 141 & -0.053 & 0.535 \\
\hline Copeptin & \multirow[t]{3}{*}{ Mean saturation } & 144 & -0.146 & 0.080 \\
\hline proANP & & 144 & -0.221 & 0.008 \\
\hline proADM & & 144 & -0.312 & $<0.001$ \\
\hline Copeptin & \multirow[t]{3}{*}{ Hypoxemia duration } & 139 & 0.105 & 0.218 \\
\hline proANP & & 139 & 0.115 & 0.177 \\
\hline proADM & & 139 & 0.297 & $<0.001$ \\
\hline Copeptin & \multirow[t]{3}{*}{$\mathrm{AHI}$} & 145 & 0.153 & 0.067 \\
\hline proANP & & 145 & 0.077 & 0.359 \\
\hline proADM & & 145 & 0.154 & 0.064 \\
\hline Copeptin & \multirow[t]{3}{*}{ PLMI } & 90 & 0.045 & 0.677 \\
\hline proANP & & 90 & 0.120 & 0.261 \\
\hline proADM & & 90 & 0.259 & 0.014 \\
\hline Copeptin & \multirow[t]{3}{*}{ Sleep latency } & 95 & -0.216 & 0.035 \\
\hline proANP & & 95 & -0.052 & 0.618 \\
\hline proADM & & 95 & 0.006 & 0.951 \\
\hline Copeptin & \multirow[t]{3}{*}{ Sleep efficiency } & 94 & 0.198 & 0.055 \\
\hline proANP & & 94 & -0.155 & 0.135 \\
\hline proADM & & 94 & -0.250 & 0.015 \\
\hline Copeptin & VAS-general well being & 70 & 0.133 & 0.271 \\
\hline
\end{tabular}




\begin{tabular}{|c|c|c|c|c|}
\hline proANP & & 70 & 0.033 & 0.789 \\
\hline proADM & & 70 & 0.054 & 0.659 \\
\hline Copeptin & ESS & 144 & 0.010 & 0.906 \\
\hline proANP & & 144 & 0.057 & 0.498 \\
\hline proADM & & 144 & -0.033 & 0.692 \\
\hline
\end{tabular}

ODI= Oxygen Desaturation Index, AHI= Apnea Hypopnea Index, PLMI= Periodic Limb Movements of Sleep, VAS=visual analogue scale, ESS= Epworth Sleepiness Scale, rho= Spearman Correlation coefficient

\section{Comparison of prohormone levels in patients with OSA before and on CPAP therapy}

In patients with OSA, the levels of proADM changed after 1 month on CPAP therapy when compared to baseline $(p<0.001)$ and decreased after 6 months on CPAP therapy $(p=0.020$, Table 3$)$. Additionally, proANP levels decreased after 12 hours on CPAP therapy, when compared to baseline $(p<0.001$, Table 3$)$. Those changes were significant, irrespective of disease severity (as assessed by the AHI and ODI scores) and the existence of symptoms (as assessed by the ESS score, Supplementary table 3). The levels of copeptin did not significantly change on CPAP treatment compared to baseline (Table 3). Adjustments for all comorbidities, time on CPAP and efficacy of treatment (as assessed by the AHI and the ESS) did not change these results. Exclusion of the 12 OSA and 1 control subjects with heart failure did not change reported results on proADM and proANP. 


\section{Table 3}

Differences in copeptin, proANP, proADM levels in patients with OSA between different visits.

\begin{tabular}{|llll|}
\hline Paired comparison & $\begin{array}{l}\text { Number of } \\
\text { pairs }\end{array}$ & $\begin{array}{l}\text { Mean difference } \pm \text { SD of the } \\
\text { difference }\end{array}$ & $\begin{array}{l}\text { p-value } \\
\text { (Wilcoxon signed } \\
\text { rank test) }\end{array}$ \\
$\begin{array}{l}\text { Copeptin baseline vs 12h } \\
\text { CPAP }\end{array}$ & 82 & $-0.59 \pm 2.98$ & 0.139 \\
\hline $\begin{array}{l}\text { Copeptin baseline vs 1 } \\
\text { month CPAP }\end{array}$ & 101 & $-0.02 \pm 4.13$ & 0.551 \\
\hline $\begin{array}{l}\text { Copeptin baseline vs 6 } \\
\text { months CPAP }\end{array}$ & 70 & $0.44 \pm 4.60$ & 0.428 \\
$\begin{array}{l}\text { proADM baseline vs 12h } \\
\text { CPAP }\end{array}$ & 82 & $0.01 \pm 0.08$ & 0.114 \\
\hline $\begin{array}{l}\text { proADM baseline vs 1 } \\
\text { month CPAP }\end{array}$ & 102 & $0.03 \pm 0.62$ & $<0.001$ \\
\hline $\begin{array}{l}\text { proADM baseline vs 6 } \\
\text { months CPAP }\end{array}$ & 72 & $-0.04 \pm 0.12$ & 0.020 \\
\hline $\begin{array}{l}\text { proANP baseline vs 12h } \\
\text { CPAP }\end{array}$ & 82 & $-7.19 \pm 19.18$ & $<0.001$ \\
\hline $\begin{array}{l}\text { proANP baseline vs 1 month } \\
\text { CPAP }\end{array}$ & 103 & $1.68 \pm 27.10$ & 0.504 \\
\hline $\begin{array}{l}\text { proANP baseline vs 6 } \\
\text { months CPAP }\end{array}$ & 72 & $2.82 \pm 30.95$ & 0.277 \\
\hline
\end{tabular}

\section{Discussion}

In this study, we hypothesised that proANP, proADM and copeptin levels are significantly higher in patients with OSA, when compared to patients without OSA. Our results indicated that only copeptin levels differed significantly among patients with and without OSA at baseline. We found a significant circadian variation in the levels of proADM, which increased in the evening and proANP, which decreased in the evening. In patients with OSA, the levels of proADM significantly changed after 1 and 6 months on CPAP therapy, when compared to baseline. Additionally, proANP levels significantly decreased after 12 hours on CPAP therapy, as compared to baseline levels. Those changes were significant irrespective of disease severity and the existence of symptoms.

The current findings come in partial agreement with the results of Cinarka et al, (31) who demonstrated that copeptin levels were higher in 116 patients with OSA, when compared to 27 controls. However, they also proposed that copeptin levels in OSA patients with $\mathrm{AHI} \geq 30$ were significantly higher when compared to OSA patients with $\mathrm{AHI}<30$ and that copeptin levels can be used as a predictor for severe OSA, being weakly correlated with AHI, ODI, arousal index and CRP. Our results, conversely, indicated that 
copeptin levels are significantly correlated with neither AHI nor ODI and that copeptin levels are not significantly different among patients with mild, moderate and severe OSA. These discrepancies might be attributed to specific patient characteristics in both studies as well as the lack of information about whether patients included in the Cinarka study were on CPAP therapy at the time when copeptin levels were measured. (31)

We found a circadian rhythm in the levels of proADM, which increased in the evening and in the levels of proANP which decreased in the evening. Indeed, in previous studies proADM and proANP demonstrated circadian variations. (32-34) However, copeptin did not present with a circadian variation, which is in line with the study of Darzy et al. (35)

Conflicting results exist about the effects of CPAP therapy on plasma proADM levels in OSA patients. In a study by Schulz et al. including 41 OSA patients and 28 controls without sleep-disordered breathing, OSA patients had markedly elevated ADM concentrations at baseline when compared to the controls. (36) After two nights of CPAP therapy, in 28 OSA patients ADM levels significantly decreased when compared to pre-CPAP values, and after 8 months of CPAP treatment, in 11 OSA patients, ADM levels further declined to levels similar with the controls. (36) On the other hand, in a small study including 15 OSA patients and 10 controls, Wolk et al. could not find any difference between ADM levels at baseline and ADM levels after 4 hours of CPAP therapy. (37) In our study, we included a larger number of patients and controls and demonstrated that there was no significant difference in proADM levels among patients with and without OSA and that in patients with OSA, proADM levels significantly changed after 1 month on CPAP therapy and significantly decreased after 6 months on CPAP therapy, when compared to baseline. Adjustments for all comorbidities, hours on CPAP and efficacy of treatment (as assessed by the AHI and the ESS on CPAP) did not change these results. ADM is secreted from various organs and is mainly produced by vascular endothelial cells, playing an important role as a vasodilator, positive inotropic, diuretic, natriuretic and bronchodilator. $(38,39)$ Several stimuli, such as hypoxia, shear stress and inflammatory cytokines can induce proADM production and all these stimuli are increased in patients with OSA. (40) Moreover, it has been identified as a prognostic marker able to stratify mortality risk in sepsis patients with different degrees of organ failure, (41) to predict all-cause mortality in pulmonary embolism (42) and increased complications and higher mortality rates in patients suffering from community acquired pneumonia. (43) OSA-induced hypoxic stress and oxidative stress increase circulating inflammatory mediators, including adhesion molecules, inflammatory cytokines and C-reactive protein, leading to hypertension and cardiovascular events. $(44,45)$ This stress and the related inflammatory molecules are implicated in the production of adrenomedullin which is a potent vasodilator. (46) Adrenomedullin has also been associated with the magnitude of oxyhemoglobin desaturation in OSA patients and with production of reactive oxygen species by leukocytes and treatment with nasal CPAP reduced these parameters in patients with OSA. (47) Therefore, it seems that the upregulation of proADM in OSA constitutes an adaptive counteractive mechanism to protect against cardiovascular diseases in patients with OSA. The reversal of the pathophysiological mechanisms of OSA by implementing non-invasive ventilation might in turn explain the longitudinal decrease of ProADM observed in patients on CPAP therapy. 
Previous studies investigating ANP levels in OSA demonstrated that treatment with CPAP acutely reduces plasma ANP levels. $(34,48)$ We also demonstrated that in 82 patients with OSA, proANP levels significantly decreased after 12 hours on CPAP therapy, as compared to baseline levels. Those changes were significant irrespective of disease severity and the existence of symptoms. That comes, nonetheless, in contrast with the results of Mackay et al, who demonstrated that in 9 patients with OSAS, treatment with CPAP for 2 days did not decrease plasma ANP levels. (49) Nevertheless, the study of Mackay et al. included a very small number of patients, when compared to our study. Other studies, could not find any association between OSA and plasma ANP levels (50-52) or even found inverse relations between plasma ANP and AHI. (49) Similarly, in our study, proANP levels were not significantly different between patients with and without OSA, and furthermore, proANP levels were not significantly associated with the severity of OSA, as assessed by the AHI.

A potential limitation of our study is the relatively short follow-up period. A longer term of treatment would have provided a better insight to the effect of CPAP on the prohormone levels. However, compared to previous studies, $(36,37,49-52)$ this follow up period was the longest. Moreover, the sample size was estimated based on changes in copeptin levels and thus a beta error for proADM and proANP levels cannot be excluded. Nevertheless, no other study so far has investigated proADM and proANP level changes in such a large group of OSA patients. Another limitation of our study is that we utilized only standardised diagnostic and therapeutic methods for OSA and that prohormone levels were measured only in five different time points and not hourly. Yet, to our knowledge, this is the first study that has investigated proADM, proANP and copeptin levels in various time points in a large group of fully characterised OSA patients.

\section{Conclusion}

The results of our study indicate that copeptin is significantly associated with the presence of OSA. None of the three biomarkers reflects disease severity. ProANP serum levels might serve as a potential proxy for the acute response to non-invasive ventilation (12 hours), while proADM reflects the long-term response to CPAP therapy ( 1 and 6 months). This is the first trial that has investigated proADM, proANP and copeptin levels in various time points in a large group of fully characterized OSA patients and the results are of great importance for sleep and respiratory physicians.

\section{Abbreviations}

AHI: apnea-hypopnea index

ANP: atrial natriuretic peptide

AVP: arginine vasopressin

CPAP: continuous positive airway pressure 
ESS: Epworth sleepiness scale

ODI: oxygen desaturation index

OSA: obstructive sleep apnea

OSAS: obstructive sleep apnea syndrome

proADM: pro-adrenomedullin

proANP: pro-atrial natriuretic peptide

proAVP: pro-arginine vasopressin

\section{Declarations}

\section{Ethics approval and consent to participate:}

All patients consent to participate in the study. The study was approved by the ethics committee of the University Hospital, Basel (EKBB 17010) and was conducted in accordance with the principles of the Helsinki declaration.

\section{Consent for publication:}

All patients signed informed consents for publication of their data in the study.

\section{Availability of data and materials:}

The datasets used and analysed during the current study are available from the corresponding author on reasonable request.

\section{Funding:}

The study was primarily funded by the Clinic of Respiratory Medicine and Pulmonary Cell Research of the University Hospital Basel, Switzerland.

\section{Competing interests:}

All authors declare that they have no competing interests.

\section{Author contributions:}

Data collection, data analysis, accuracy of data, statistical analysis, writing of the manuscript, contribution to the discussion of results, finalization of the manuscript and approval of the submitted article: MK, PG, WS, TS, KJ, LG, MT, DS; conception of the research project, contribution in clinical work, integrity and accuracy of data, preparation and approval of the submitted article: DS. 
Acknowledgments:

not applicable

\section{Guarantor statement:}

D. Stolz takes full responsibility for the content of the manuscript, including the data and the analysis thereof.

\section{References}

1. Young T, Peppard PE, Gottlieb DJ. Epidemiology of obstructive sleep apnea: a population health perspective. Am J Respir Crit Care Med. 2002;165(9):1217-1239.

2. Narkiewicz K, van de Borne PJ, Pesek CA, Dyken ME, Montano N, Somers VK. Selective potentiation of peripheral chemoreflex sensitivity in obstructive sleep apnea. Circulation. 1999;99(9):1183-1189.

3. Narkiewicz K, Montano N, Cogliati C, van de Borne PJ, Dyken ME, Somers VK. Altered cardiovascular variability in obstructive sleep apnea. Circulation. 1998;98(11):1071-1077.

4. Karakioulaki M, Stolz D. Biomarkers in Pneumonia-Beyond Procalcitonin. Int J Mol Sci. 2019;20(8).

5. Tasci S, Manka R, Scholtyssek S, et al. NT-pro-BNP in obstructive sleep apnea syndrome is decreased by nasal continuous positive airway pressure. Clin Res Cardiol. 2006;95(1):23-30.

6. Leoni D, Rello J. Severe community-acquired pneumonia: optimal management. Curr Opin Infect Dis. 2017;30(2):240-247.

7. Pereira JM, Azevedo A, Basilio C, Sousa-Dias C, Mergulhao P, Paiva JA. Mid-regional proadrenomedullin: An early marker of response in critically ill patients with severe communityacquired pneumonia? Rev Port Pneumol. 2016;22(6):308-314.

8. Khan Al, Kato J, Ishiyama Y, Kitamura K, Kangawa K, Eto T. Effect of chronically infused adrenomedullin in two-kidney, one-clip hypertensive rats. Eur J Pharmacol. 1997;333(2-3):187-190.

9. An R, Xi C, Xu J, et al. Intramyocardial Injection of Recombinant Adeno-Associated Viral Vector Coexpressing PR39/Adrenomedullin Enhances Angiogenesis and Reduces Apoptosis in a Rat Myocardial Infarction Model. Oxid Med Cell Longev. 2017;2017:1271670.

10. Fujii T, Nagaya $N$, Iwase $T$, et al. Adrenomedullin enhances therapeutic potency of bone marrow transplantation for myocardial infarction in rats. Am J Physiol Heart Circ Physiol. 2005;288(3):H1444-1450.

11. Nakamura R, Kato J, Kitamura K, et al. Adrenomedullin administration immediately after myocardial infarction ameliorates progression of heart failure in rats. Circulation. 2004;110(4):426-431.

12. Oyar EO, Kiris I, Gulmen S, et al. Adrenomedullin attenuates aortic cross-clamping-induced myocardial injury in rats. Am J Surg. 2011;201(2):226-232.

13. Yanagawa B, Kataoka M, Ohnishi S, et al. Infusion of adrenomedullin improves acute myocarditis via attenuation of myocardial inflammation and edema. Cardiovasc Res. 2007;76(1):110-118. 
14. Okumura $\mathrm{H}$, Nagaya $\mathrm{N}$, Itoh $\mathrm{T}$, et al. Adrenomedullin infusion attenuates myocardial ischemia/reperfusion injury through the phosphatidylinositol 3-kinase/Akt-dependent pathway. Circulation. 2004;109(2):242-248.

15. Yin $\mathrm{H}$, Chao $\mathrm{L}$, Chao J. Adrenomedullin protects against myocardial apoptosis after ischemia/reperfusion through activation of Akt-GSK signaling. Hypertension. 2004;43(1):109-116.

16. Yoshizawa T, Takizawa S, Shimada S, Tokudome T, Shindo T, Matsumoto K. Effects of Adrenomedullin on Doxorubicin-Induced Cardiac Damage in Mice. Biol Pharm Bull. 2016;39(5):737746.

17. Asfar $P$, Hauser $B$, Radermacher $P$, Matejovic M. Catecholamines and vasopressin during critical illness. Crit Care Clin. 2006;22(1):131-149, vii-viii.

18. Itoi K, Jiang YQ, Iwasaki Y, Watson SJ. Regulatory mechanisms of corticotropin-releasing hormone and vasopressin gene expression in the hypothalamus. J Neuroendocrinol. 2004;16(4):348-355.

19. de Bree FM, Burbach JP. Structure-function relationships of the vasopressin prohormone domains. Cell Mol Neurobiol. 1998;18(2):173-191.

20. de Bold AJ. Atrial natriuretic factor: a hormone produced by the heart. Science. 1985;230(4727):767770 .

21. Levin ER, Gardner DG, Samson WK. Natriuretic peptides. N Engl J Med. 1998;339(5):321-328.

22. Pandey KN. Natriuretic peptides and their receptors. Peptides. 2005;26(6):899-900.

23. Sundsfjord JA, Thibault G, Larochelle P, Cantin M. Identification and plasma concentrations of the Nterminal fragment of proatrial natriuretic factor in man. J Clin Endocrinol Metab. 1988;66(3):605-610.

24. Morgenthaler NG, Struck J, Thomas B, Bergmann A. Immunoluminometric assay for the midregion of pro-atrial natriuretic peptide in human plasma. Clin Chem. 2004;50(1):234-236.

25. Klinger JR, Pietras $L$, Warburton R, Hill NS. Reduced oxygen tension increases atrial natriuretic peptide release from atrial cardiocytes. Exp Biol Med. 2001;226(9):847-853.

26. Lang RE, Tholken H, Ganten D, Luft FC, Ruskoaho H, Unger T. Atrial natriuretic factor-a circulating hormone stimulated by volume loading. Nature. 1985;314(6008):264-266.

27. Kapur VK, Auckley DH, Chowdhuri S et al. Clinical practice guideline for diagnostic testing for adult obstructive sleep apnea: an American academy of sleep medicine clinical practice guideline. J Sleep Med. 2017;13(3):479-504.

28. Morgenthaler NG, Struck J, Alonso C, et al. Assay for the measurement of copeptin, a stable peptide derived from the precursor of vasopressin. Clin Chem 2006;52:112-119

29. Morgenthaler NG, Struck J, Thomas B, et al. Immunoluminometric assay for the midregion of proatrial natriuretic peptide in human plasma. Clin Chem 2004; 50: 234-236.

30. Morgenthaler NG, Struck J, Alonso C, Bergmann A. Measure- ment of midregional proadrenomedullin in plasma with an immunoluminometric assay. Clin Chem 2005;51:1823-1829.

31. Cinarka $H$, Kayah S, Karatas $M$, et al. Copeptin: a new predictor for severe obstructive sleep apnea. Ther Clin Risk Manag. 2015;11:589-594. 
32. Suzuki Y, Itoh Hiroki, Katagiri F, et al. Development and clinical application of an enzyme immunoassay for the determination of midregional proadrenomedullin. J. Pept. Sci. 2013; 19:59-63

33. Winters CJ, Sallman AL, Vesely DL: Circadian rhythm of pro- hormone atrial natriuretic peptides 1-30, 31-67, and 99-126 in man. Chronobiol Int 1988,5:403-409.

34. Lin CC, Tsan KW, Lin CY. Plasma levels of atrial natriuretic factor in moderate to severe obstructive sleep apnea syndrome. Sleep. 1993;16(1):37-39.

35. Darzy KH, Dixit KC, Shalet SM, et al. Circadian secretion pattern of copeptin, the C-terminal vasopressin precursor fragment. Clin Chem.2010;56:1190-1191.

36. Schulz R, Flototto C, Jahn A, et al. Circulating adrenomedullin in obstructive sleep apnea. J Sleep Res. 2006;15(1):89-95.

37. Wolk R, Svatikova A, Otto ME, Hoffmann MS, Duenwald CJ, Somers VK. Plasma adrenomedullin and obstructive sleep apnea. Am J Hypertens. 2004;17(1):74-76.

38. Kitamura K, Kangawa K, Eto T. Adrenomedullin and PAMP: Discovery, Structures, and Cardiovascular Functions. Microsc Res Tech. 2002;57:3-13.

39. Brain SD. Vascular Actions of Calcitonin Gene-Related Peptide and Adrenomedullin. Physiol. Rev. 2004;84:903-934.

40. Minoguchi K, Adachi M. The role of adrenomedullin in obstructive sleep apnea. Hypertens Res. 2007; 30:1007-1008.

41. Onal U, Valenzuela-Sanchez F, Vandana KE, Rello J. Mid-regional pro-adrenomedullin (MR-proADM) as a biomarker for sepsis and septic shock: Narrative review. Healthcare. 2018;6(3):110

42. Pedowska-Wloszek J, Kostrubiec M, Kurnicka K, et al. Midredional proadrenomedullin (MR-proADM) in the risk stratification of patients with acute pulmonary embolism. Thromb Res. 2013;132(5):50610.

43. Liu D, Xie L, Zhao H, Liu X, Cao J. Prognostic value or mid-regional pro-adrenomedullin (MR-proADM) in patients with community-acquired pneumonia: a systematic review and meta-analysis. BMC Infect Dis. 2016;16:232

44. Ohga E, Nagase T, Tomita T et al. Increased levels of circulating ICAM-1, VCAM-1, and L-selectin in obstructive sleep apnea syndrome. J Appl Physiol. 1999;87:10-14.

45. Teramoto S,Yamamoto H,Ouchi Y.Increased C-reactive protein and increased plasma interleukin-6 may synergistically affect the progression of coronary atherosclerosis in obstructive sleep apnea syndrome. Circulation. 2003;107:E40.

46. Sugo S, Minamino N, Kangawa K et al. Endothelial cells actively synthesize and secrete adrenomedullin. Biochem Biophys Res Commun. 1994;201:1160-1166.

47. Yamamoto $H$, Teramoto $S$, Yamaguchi $Y$, Ouchi Y. Effect of nasal continuous positive airway pressure treatment on plasma adrenomedullin levels in patients with obstructive sleep apnea syndrome: roles of noctunrnal hypoxia and oxidant stress, Hypertens Res. 2007;30:1065-1076 
48. Krieger J, Follenius M, Sforza E, Brandenberger G, Peter JD. Effects of treatment with nasal continuous positive airway pressure on atrial natriuretic peptide and arginine vasopressin release during sleep in patients with obstructive sleep apnea. Clin Sci. 1991;80(5):443-449.

49. Mackay TW, Fitzpatrick MF, Freestone S, Lee MR, Douglas NJ. Atrial natriuretic peptide levels in the sleep apnea/hypopnoea syndrome. Thorax. 1994;49(9):920-921.

50. Moller DS, Lind P, Strunge B, Pedersen EB. Abnormal vasoactive hormones and 24-hour blood pressure in obstructive sleep apnea. Am J Hypertens. 2003;16(4):274-280.

51. Patwardhan AA, Larson MG, Levy D, et al. Obstructive sleep apnea and plasma natriuretic peptide levels in a community-based sample. Sleep. 2006;29(10):1301-1306.

52. Schafer H, Ehlenz K, Ewig S, et al. Atrial natriuretic peptide levels and pulmonary artery pressure awake, at exercise and asleep in obstructive sleep apnea syndrome. J Sleep Res. 1999;8(3):205-210.

\section{Figures}

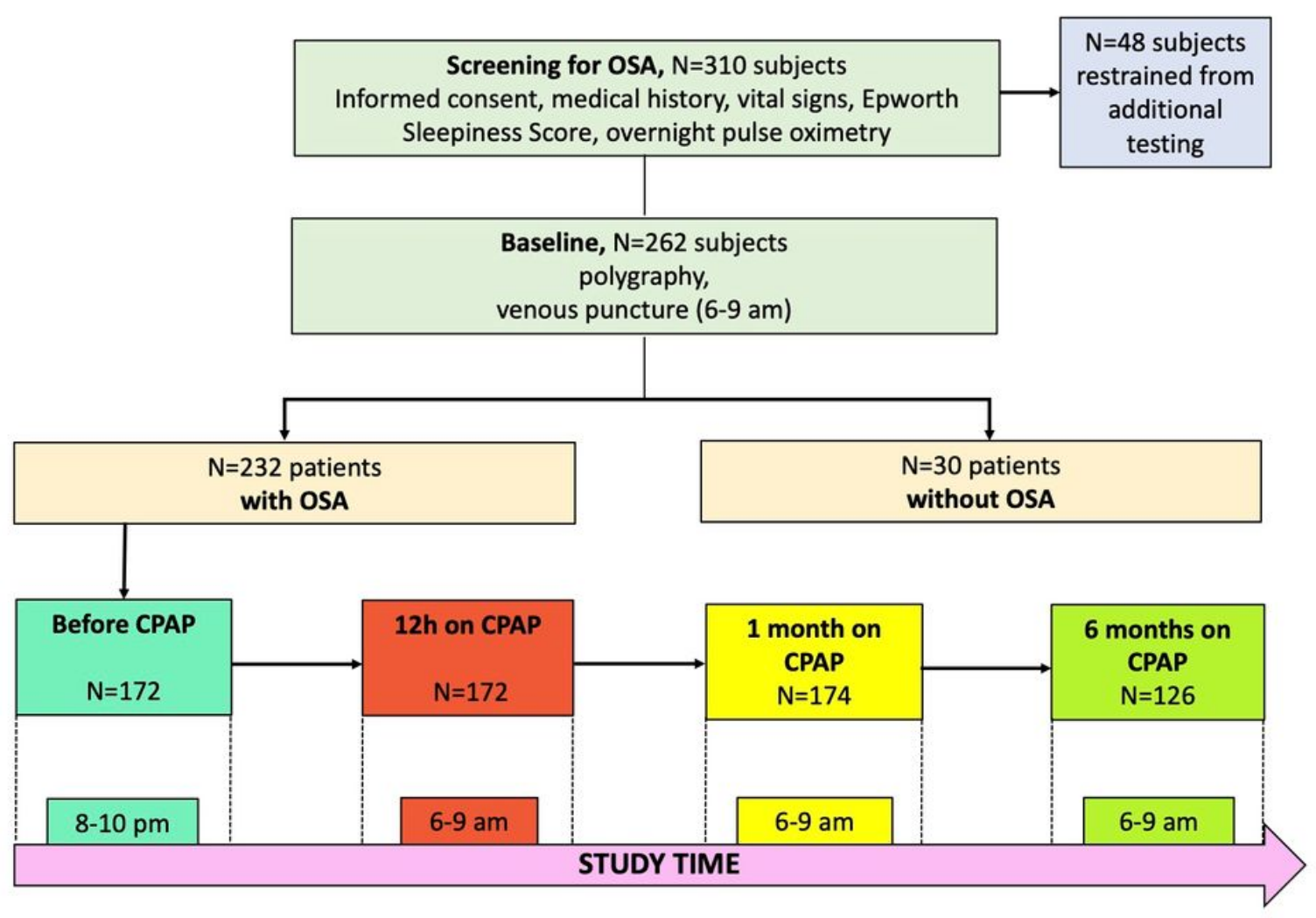

\section{Figure 1}

Study design 

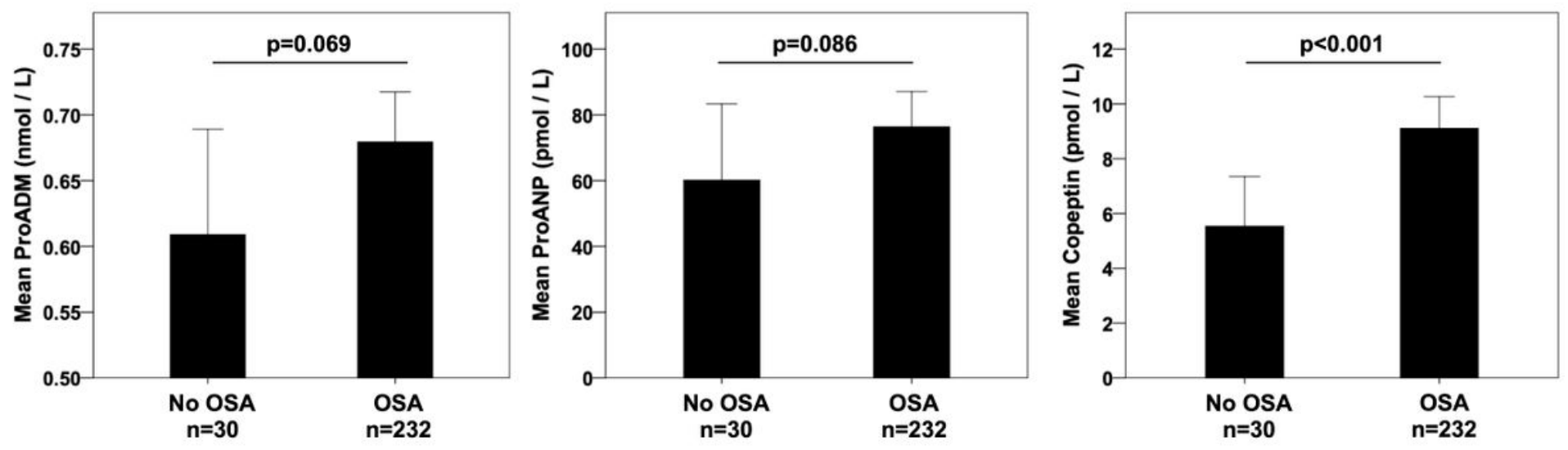

Figure 2

Differences at biomarker levels among patients with and without OSA at baseline. Error bars represent 95\% Confidence Intervals. p-values were calculated using the Mann Whitney U test.
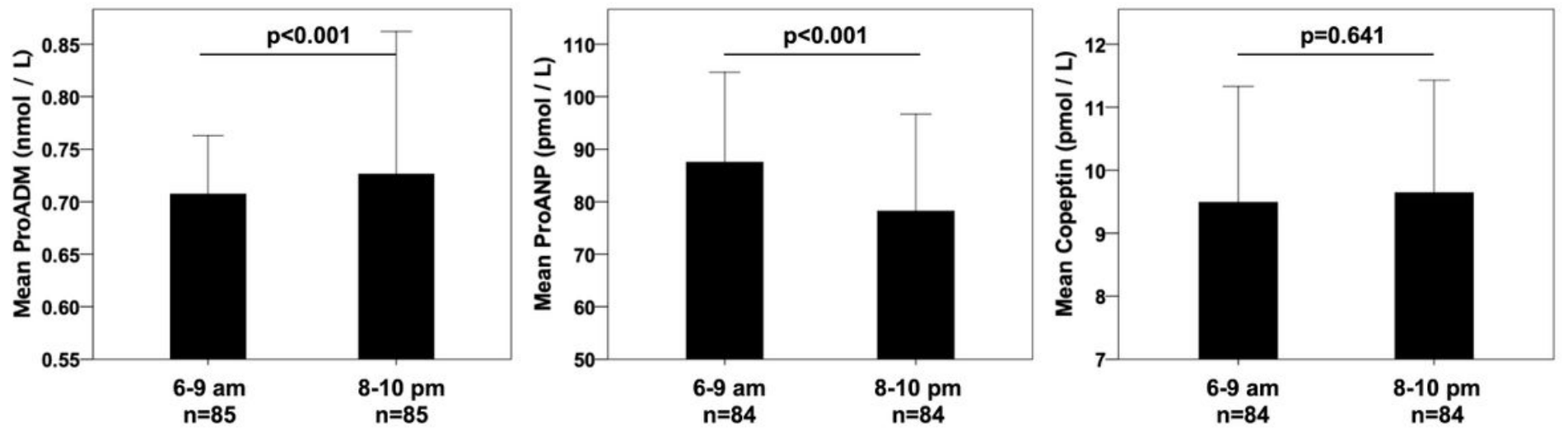


\section{Figure 3}

Circadian variation of biomarker levels in patients with OSA between morning (6-9am) and evening (8$10 \mathrm{pm}$ ) hours. Error bars represent $95 \%$ Confidence Intervals. p-values were calculated using the Wilcoxon signed rank test.

\section{Supplementary Files}

This is a list of supplementary files associated with this preprint. Click to download.

- SupplementaryTables.docx 